\title{
Understanding Interactions in Social Networks and Committees *
}

\author{
Arnab Bhattacharjee ${ }^{\$}$ and Sean Holly $\# \dagger$
}

October 13, 2008

\begin{abstract}
While much of the literature on cross section dependence has focused mainly on estimation of the regression coefficients in the underlying model, estimation and inferences on the magnitude and strength of spill-overs and interactions has been largely ignored. At the same time, such inferences are important in many applications, not least because they have structural interpretations and provide useful interpretation and structural explanation for the strength of any interactions. In this paper we propose GMM methods designed to uncover underlying (hidden) interactions in social networks and committees. Special attention is paid to the interval censored regression model. Our methods are applied to a study of committee decision making within the Bank of England's monetary policy committee.
\end{abstract}

JEL Classification: D71, D85, E43, E52, C31, C34.

Keywords: Committee decision making; Social networks; Cross section and spatial interaction; Generalised method of moments; Censored regression model; Expectation-Maximisation Algorithm; Monetary policy; Interest rates.

*Correspondence: A.Bhattacharjee, School of Economics and Finance, University of St. Andrews, Castlecliffe, The Scores, St. Andrews KY16 9AL, UK; Tel: 44-1334-462423; Fax: 44-1334-462444; Email: ab102@st-andrews.ac.uk.

This paper is very much work-in-progress. Any comments or suggestions are most welcome. The usual disclaimer applies.

$\dagger \$$ University of St. Andrews, UK; \# University of Cambridge, UK. 


\section{Introduction}

Various approaches have been proposed in the literature to address cross section, or spatial, dependence. At the one end are multifactor approaches which assume cross section dependence can be explained by a finite number of unobserved common factors that affect all units (regions, economic agents, etc.). Estimation of panel data regression models under such factor error structure has been addressed by maximum likelihood (Robertson and Symons, 2000), principal component analysis (Coakley et al., 2002), or the recently proposed common correlated effects approach (Pesaran, 2006).

An alternative characterisation, originally developed in the regional science and geography literatures, but with increasing economic applications, is based on spatial weights matrices. The idea is that there are spillover effects across the economic agents because of spatial or other forms of local cross section dependence. Panel data regression models with such spatially correlated error structures have been estimated using maximum likelihood techniques (Anselin, 1988), or generalized method of moments (Kapoor et al., 2007; Kelejian and Prucha, 1999; Conley, 1999). Kelejian and Prucha (2007) also extend the GMM methodology to nonparametric estimation of heteroscedasticity and autocorrelation consistent cross section covariance matrix, for applications where an instrumental variable procedure has been used to estimate the regression coefficients.

However, the above two characterisations of cross section dependence are not mutually exclusive. Factor models typically only provide a partial expanation for cross section dependence, and therefore it is often observed that residuals from estimated factor models display substantial cross section correlation. Furthermore, Pesaran and Tosetti (2007) consider a panel data model where both sources of cross section dependence exist and show that, under certain restrictions on the nature of dependence, the common correlated effects approach (Pesaran, 2006) still works.

At the same time as spatial weights characterise cross section dependence in useful ways, their accurate measurement has a significant effect on the estimation of a spatial dependence model (Anselin, 2002; Fingleton, 2003). Measurement is typically based on underlying notions of distances between cross section units. These differ widely across applications, depending not only on the specific economic context but also on availability of data. Spatial contiguity (resting upon implicit assumptions about contagious processes) using a binary representation is a frequent choice. Further, in many applications, 
there are multiple possible choices and substantial uncertainty regarding the appropriate choice of distance measures. However, while the existing literature contains an implicit acknowledgment of these problems, most empirical studies treat spatial dependence in a superficial manner assuming inflexible diffusion processes in terms of known, fixed and arbitrary spatial weights matrices (Giacomini and Granger, 2004). The problem of choosing spatial weights becomes a key issue in many economic applications; apart from geographic distances, notions of economic distance (Conley, 1999; Pesaran et al., 2004, Holly et al., 2008), socio-cultural distance (Conley and Topa, 2002; Bhattacharjee and Jensen-Butler, 2005), and transportation costs and time (Gibbons and Machin, 2005; Bhattacharjee and Jensen-Butler, 2005) have been highlighted in the literature. The uncertainty regarding the choice of metric space and location, closely related to the measurement of spatial weights, have been addressed in the literature (Conley and Topa, 2002, 2003; Conley and Molinari, 2007). Related issues regarding endogeneity of locations have also been addressed (Pinkse et al., 2002; Kelejian and Prucha, 2004; Pesaran and Tosetti, 2007).

While the above literature addressed cross section dependence in various ways, it has focused mainly on estimation of the regression coefficients in the underlying model, treating the cross section dependence as a nuisance parameter. Estimation and inferences on the magnitude and strength of spillovers and interactions has been largely ignored. However, there are many instances in which inferences about the nature of the interaction is of independent interest. Recent developments in the economics of networks (Goyal, 2007) suggest that the pattern of connections between individual rational agents shapes their actions and determines their rewards. Understanding, empirically, what the precise form of interaction is actually observed is an important counterpart to the development of the theory of networks.

Bhattacharjee and Jensen-Butler (2005) consider estimation of spatial weights matrix in a spatial error model with spatial autoregressive errors. They show that the estimation problem is only partially identified, upto the choice of an arbitrary orthogonal transformation of the interactions. This problem is related to identification restrictions underlying the factor model (Bonhomme and Robin, 2006) and simultaneous equation systems (Hausman and Taylor, 1983; Hausman et al., 1987). Symmetry of the spatial weights matrix constitutes one set of valid identifying restrictions.

However, such identifying restrictions may be too strong in some applications. In this paper, we develop a GMM based estimation methodology 
for spatial or interaction weights matrices which are unrestricted except for the validity of the included instruments and other moment conditions. Furthermore, instrument validity can be tested in our framework, in addition to the identification restrictions required for the estimators proposed in Bhattacharjee and Jensen-Butler (2005). Specifically, we consider a setup where a given set of cross section units have fixed but unrestricted interactions; these interactions are inherently structural in that they are related to an underlying structural economic model. Further, there exist a set of other cross section units, correlated with the units under consideration, but which may change over time, expand or even vanish. In fact, our estimation methodology, motivated by the system GMM approach (Arellano and Bond, 1991; Blundell and Bond, 1998), uses these additional units to constitute instruments. Additional instruments can be included under the assumption of homoscedasticity. While the basic method is based on a multiple regression model with spatial autoregressive errors, we also consider three extensions. In the first, we extend our estimates to the censored regression model. Secondly, we allow for unobserved common factors in addition to idiosyncratic errors with spatial interactions. Finally, we consider a regression model with spatial autoregressive structure in the regressors in addition to cross section dependent errors.

Our methods are applied to a study of committee decision making within the Bank of England's monetary policy committee (MPC). We consider a monetary policy committee where personalities are important. In our model of committee decision making, the personalities are reflected in heterogeneity in the policy reaction functions for the different members, as well as in interactions among members that can be strategic or just a reflection of likemindedness. We extend the work in Bhattacharjee and Holly (2008) by considering heterogeneity in the beliefs about the effects of interest rates on output and inflation, in the private information of each committee member and in their differing views on uncertainty. Further, we allow for interaction between the members of the committee. Our estimates suggest significant cross section interactions between members, both positive and negative. 


\section{Model and GMM estimators}

We consider a panel data model with fixed effects and unrestricted slope heterogeneity

$$
\begin{aligned}
& y_{i t}=\eta_{i}+\alpha_{i}^{\prime} d_{t}+\beta_{i}^{\prime} x_{i t}+e_{i t}, \quad i=1,2, \ldots, N ; t=1,2, \ldots, T \\
& E\left(e_{i t}\right)=0 ; V\left(e_{i t}\right)=\sigma_{i}^{2} ; \operatorname{Cov}\left(\eta_{i}, e_{i t}\right)=0 \\
& E\left(e_{i t} \cdot e_{i s}\right)=0 \quad i=1,2, \ldots, N ; t \neq s .
\end{aligned}
$$

Note that the regression errors are allowed to have arbitrary cross section dependence. In fact our main objective here is to provide estimates of the interactions between the cross section units.

There are a variety of estimators in the literature for the regression coefficients of the above model; see, for example, Anselin (1988) and Anselin et al. (2003) and references therein. In particular, in the case when $N$ is not large the SURE method allows for unrestricted correlations across cross section units, and provides a simple way to test for slope heterogeneity in the regression coefficients.

Our focus, however, is on modelling the network between the agents $1,2, \ldots, N$, and estimation of cross agent interactions. This is a problem that has not received much attention in the literature. For this purpose, we propose the model

$$
\begin{aligned}
e_{1 t}= & w_{12} e_{2 t}+w_{13} e_{3 t}+\ldots+w_{1 N} e_{N t}+u_{1 t} \\
e_{2 t}= & w_{21} e_{1 t}+w_{23} e_{3 t}+\ldots+w_{2 N} e_{N t}+u_{2 t} \\
& \vdots \\
e_{N t}= & w_{N 1} e_{1 t}+w_{N 2} e_{2 t}+\ldots+w_{N,(N-1)} e_{N-1, t}+u_{N t},
\end{aligned}
$$

or, in compact form

$$
e_{t}=W e_{t}+u_{t}
$$

where $W$ is a $(N \times N)$ matrix of interaction weights with zero diagonal elements and unrestricted entries on the off-diagonals. The only condition that $W$ needs to satisfy is that $(I-W)$ is non-singular, which is required for identification in the reduced form.

The interaction weights matrix $W$ is related to the spatial weights matrix popular in geography, regional sciences and in the spatial econometrics 
literature. However, while that literature treats $W$ as exogenous and known a priori, at least approximately, our interpretation differs. For us, $W$ is a matrix of interaction weights which is unknown and on which we conduct inference. One way to motivate the framework is network theory (Dutta and Jackson, 2003; Goyal, 2007), where the equilibrium network emerges through interactions between agents.

We will propose GMM based estimators for these weights. Towards this end, we consider first a somewhat analogous setup from the literature on the standard dynamic panel data model, described as

$$
\begin{aligned}
& y_{i t}=\eta_{i}+\alpha y_{i, t-1}+e_{i t}, \quad i=1,2, \ldots, N ; t=1,2, \ldots, T \\
& E\left(\eta_{i}\right)=0 ; E\left(e_{i t}\right)=0 ; E\left(\eta_{i} e_{i t}\right)=0 ; \\
& E\left(e_{i t} . e_{i s}\right)=0 \quad i=1,2, \ldots, N ; t \neq s .
\end{aligned}
$$

Arellano and Bond (1991) considered GMM estimation of the above model based on sequential moment conditions where lagged levels of the variable are instruments for the endogenous first differences. Under the initial condition that

$$
E\left(y_{i 1} \cdot e_{i t}\right)=0 \quad i=1,2, \ldots, N ; t=2,3, \ldots, T
$$

Arellano and Bond (1991) proposed the $(T-1)(T-2) / 2$ linear moment conditions

$$
E\left(y_{i}^{(t-2)} . \triangle e_{i t}\right)=0 \quad t=3, \ldots, T,
$$

where $y_{i}^{(t-2)}=\left(y_{i 1}, y_{i 2}, \ldots, y_{i, t-2}\right)$.

Our context is different. We have lagged endogenous variables as regressors, but the observations are not sampled at equi-spaced points on the time axis. Rather, the locations of our agents lie in a multi-dimensional, and possibly abstract, space without any clear notion of ordering or spacing between observations. At the same time, one can often imagine that potential nonzero interaction weights imply that $e_{1 t}, e_{2 t}, \ldots, e_{N t}$ are regression errors from (1), at time $t$, on a collection of agents who are not located very far away in space. In many applications, there may also be, potentially specific to the time period, additional agents who are located further away (like those at higher lags in the dynamic panel data model), who are correlated with the above set of 
endogenous variables, but not with the idiosyncratic errors $u_{1 t}, u_{2 t}, \ldots, u_{N t}$ from the spatial error equation (2).

In social networks agents who have weak ties with other agents may act as instruments for groups of agents that share strong ties (Granovetter, 1973, Goyal, 2005) In panel data on cross-sections of countries or regions, such a set may include other countries not included in the analysis either because of irregular availability of data or because they are outside the purview of the analysis. Similarly, in geography and regional studies, observations at a finer spatial scale may constitute such instruments. We denote such a collection of instruments, specific to a particular time $t$, by $\bar{e}_{i}^{(t)}=\left(e_{i t}^{(1)}, e_{i t}^{(2)}, \ldots, e_{i t}^{\left(k_{t}\right)}\right)$, and assume the $\sum_{t=1}^{T} k_{t}$ moment conditions

$$
E\left(\bar{e}_{i}^{(t)} \cdot u_{i t}\right)=0 \quad i=1,2, \ldots, N ; t=1,2, \ldots, T .
$$

The validity of these potentially large number of instruments can be checked using, for example, the Sargan $J$-test. However, weak instruments may also potentially provide a problem here. Similar to Arellano and Bond (1991), and assuming a first order autoregressive structure in the errors of the interaction model:

$$
\begin{aligned}
& u_{i t}=\alpha u_{i t}+\varepsilon_{i t} \quad i=1,2, \ldots, N ; t=2,3, \ldots, T, \\
& E\left(\varepsilon_{i t} \varepsilon_{i s}\right)=0 \quad t \neq s,
\end{aligned}
$$

we have the additional $N(T-1)(T-2) / 2$ linear moment conditions

$$
E\left(e^{(t-2)} \cdot u_{i t}\right)=0 \quad t=3, \ldots, T,
$$

where $e^{(t-2)}=\left(e_{1}^{(t-2)}, e_{2}^{(t-2)}, \ldots, e_{N}^{(t-2)}\right)$ and $e_{i}^{(t-2)}=\left(e_{i 1}, e_{i 2}, \ldots, e_{i, t-2}\right)$ for $i=1,2, \ldots, N$.

Further, following Ahn and Schmidt (1995) and Blundell and Bond (1998), we can assume that the $u_{i t}$ disturbances are homoscedastic over time. In this case, we have a further $N(T-2)$ moment conditions

$$
E\left(e_{i, t-2} u_{i, t-1}-e_{i, t-1} u_{i, t}\right)=0 \quad i=1,2, \ldots, N ; t=3, \ldots, T .
$$

For the model given in (1) and (2), we propose a three step estimation procedure as follows. First, we estimate the underlying regression model (1) using an optimisation based method such as maximum likelihood, least 
squares or GMM, and collect residuals. Next, we estimate the spatial error model (2) using a two-step GMM estimator. The weights matrix is estimated using the outer product from moment conditions evaluated at an initial consistent estimator, which is the GMM estimator using the identity weighting matrix. The validity of multi-step procedures such as the one proposed here follow from Newey (1984). ${ }^{1}$.

Our methods are related to some alternative approaches taken in the literature. Bhattacharjee and Jensen-Butler (2005) consider estimation of interaction weights in a framework closely related to ours, and show that these weights are only partially identified from the unrestricted pattern of cross section dependence. Additional structural assumptions, such as symmetry of the weights matrix, is required for explicit estimation of the weights matrix. Bhattacharjee and Holly (2008) apply the above method to interactions within the Bank of England's Monetary Policy Committee, using an alternative set of identifying structural restrictions. Admittedly, the above methodology requires strong, and often unverifiable, structural assumptions, which is the main limitation that the current GMM based approach seeks to address.

Pinkse et al. (2002) also consider a related problem where agents position themselves in geographical and quality space strategically, and therefore endogenously, but their relative positions are approximately given by a vector of distance measures. Their GMM methodology relies crucially on the validity of the distance metrics, which are fixed a priori. Moreover, their main focus is in estimating the underlying regression coefficients rather than the strength (and direction) of the interactions; see also Pinkse and Slade (2007). Similarly, Conley (1999) and Conley and Topa (2002) develop GMM based methodology to estimate the regression parameters of the underlying model, where there is some uncertainty in the a priori specification of distance measures.

Our work is also related to the literature on networks. While theory suggests that equilibrium network structure tends to have ceratin simple forms (see, for example, Jackson and Wolinsky, 1996; Bala and Goyal, 2003; Goyal and Vega-Redondo, 2007), our methods can be used to evaluate these

\footnotetext{
${ }^{1}$ The number of moment conditions in the methods proposed in this paper are potentially large. Following Doran and Schmidt (2006), one can effectively perform GMM on a smaller set of moment conditions by considering only the leading principal components of the weighting matrix. This is likely to improve small sample performance, though we have not explored this at present.
} 
theories and to draw inferences on the form on networks in real applications.

Next, we consider three extensions. The first is to a model where the response variable is interval censored. Our second extension is to a model (Pesaran and Tosetti, 2007) which includes unobserved factors in addition to cross section dependence. Finally, we consider a model, similar to Pinkse et al. (2002), where in addition to cross section dependence in the error structure, we also have spatial autoregression in the underlying economic model.

\subsection{Interactions between censored residuals}

Consider a DGP where the residuals from the underlying economic model are interval censored: $e_{i t} \in\left[e_{0 i t}, e_{1 i t}\right]$. Such censoring typically arises because the dependent variable, $y_{i t}$, from the underlying economic model is itself either interval censored or ordinal. Then, for a given cross section unit $i$, we have the following regression model in latent errors

$$
e_{i t}=\widetilde{e}_{(-i) t} w_{(i)}+\varepsilon_{i t}
$$

where $\widetilde{e}_{(-i)}$ denotes the vector of residuals for the cross section units other than $i, w_{(i)}$ is the $i$-th row of $W$ transposed (ignoring the diagonal element, which is zero by construction), and observations run over $t=1, \ldots, T$. Henceforth, for simpler exposition, we omit the reference to subscripts $i$ and $t$. We discuss estimation of the $w_{(i)}$, an index row of $W$. The same procedure is repeated for each cross section unit in turn, and the whole $W$ matrix is therefore estimated.

The censored regression model in the regression errors is then more simply written as

$$
\begin{aligned}
e & =\widetilde{e} w+u \\
\text { Observations } & :\left(\left[e_{0}, e_{1}\right], \widetilde{e}, z\right) \\
P\left(e \in\left[e_{0}, e_{1}\right]\right) & =1
\end{aligned}
$$

where $\bar{e}$ are endogenous regressors with instruments $z$.

We further assume that

$$
\begin{aligned}
& \widetilde{e}=z^{\prime} b+\varepsilon ; E(z \varepsilon)=0 \\
& u=\varepsilon^{\prime} \gamma+v ; v \perp u, \varepsilon ; v \sim N\left(0, \sigma_{v}^{2}\right) .
\end{aligned}
$$


An important special case when this holds is when $u$ and $\varepsilon$ are jointly normally distributed and independent of $z$. However, in general, normality of $\varepsilon$ is not required. Further, following Blundell and Powell (2004), the framework can be further generalised where $\widetilde{e}=h(z)+\varepsilon$, and the distribution of errors is unknown. In this case, estimation and inference will depend of kernel based methods and appropriate measures of choice probabilities. On the second, various options are available from the literature: purely nonparametric kernel estimates, average structural functions (Blundell and Powell, 2003) or index choice probabilities (Ichimura, 1993); see Blundell and Powell (2003) for a review and discussion. We assume linear structure and normality of the instrument equation errors for the sake of simplicity.

Substituting for $u$, the interval inequalities corresponding to $P\left(e \in\left[e_{0}, e_{1}\right]\right)=$ 1 can be expressed as

$$
\begin{aligned}
& D_{0}=1\left(-e_{0}+\widetilde{e} w+\varepsilon^{\prime} \gamma+v \geq 0\right) \text { and } \\
& D_{1}=1\left(e_{1}-\widetilde{e} w-\varepsilon^{\prime} \gamma-v \geq 0\right)
\end{aligned}
$$

\subsubsection{Exogenous censoring intervals}

First, let us assume that the boundaries of the censoring intervals $\left(e_{0}\right.$ and $\left.e_{1}\right)$ are exogenous. Exogeneity of the censoring interval is natural or otherwise a plausible assumption, in many applications. For example, event studies on firms often focus on a fixed period of time, which then corresponds to an exogenously given interval in the age of the firm or an exogenous interval in duration since a treatment under study. Another example could be study of exit, investment and acquisition decisions in firms, where the underlying model of Jovanovic and Rousseau (2002) posits four regions of firm efficiencies: the firm exits at levels below a lower threshold, continues without investment in the next, invests only in new capital at higher efficiencies, and expands through organic growth and acquisitions at efficiencies above a high threshold (see also Bhattacharjee et al., 2008). Other applications would arise from data on longitudinal surveys, where economic agents are observed over time, but typically only at fixed time points.

In the above case, $-e_{0}$ and $e_{1}$ can be treated as regressors with positive unit coefficients and the control function approach (Blundell and Smith, 
1986) can be applied. Extending Lewbel (2004), we first define

$$
\begin{aligned}
R_{0}\left(D_{0}, e_{0}, \widetilde{e}, \varepsilon, w, \gamma, \sigma_{v}\right)= & D_{0} \frac{\phi\left[\left(-e_{0}+\widetilde{e}^{\prime} w+\varepsilon^{\prime} \gamma\right) / \sigma_{v}\right]}{\Phi\left[\left(-e_{0}+\widetilde{e}^{\prime} w+\varepsilon^{\prime} \gamma\right) / \sigma_{v}\right]} \\
& +\left(1-D_{0}\right) \frac{-\phi\left[\left(-e_{0}+\widetilde{e}^{\prime} w+\varepsilon^{\prime} \gamma\right) / \sigma_{v}\right]}{1-\Phi\left[\left(-e_{0}+\widetilde{e}^{\prime} w+\varepsilon^{\prime} \gamma\right) / \sigma_{v}\right]}, \text { and } \\
R_{1}\left(D_{1}, e_{1}, \widetilde{e}, \varepsilon, w, \gamma, \sigma_{v}\right)= & D_{1} \frac{\phi\left[\left(e_{1}-\widetilde{e}^{\prime} w-\varepsilon^{\prime} \gamma\right) / \sigma_{v}\right]}{\Phi\left[\left(e_{1}-\widetilde{e}^{\prime} w-\varepsilon^{\prime} \gamma\right) / \sigma_{v}\right]} \\
& +\left(1-D_{1}\right) \frac{-\phi\left[\left(e_{1}-\widetilde{e}^{\prime} w-\varepsilon^{\prime} \gamma\right) / \sigma_{v}\right]}{1-\Phi\left[\left(e_{1}-\widetilde{e}^{\prime} w-\varepsilon^{\prime} \gamma\right) / \sigma_{v}\right]},
\end{aligned}
$$

where $\phi$ and $\Phi$ are the pdf and cdf of the standard normal distribution respectively.

The following moment conditions can then be obtained:

$$
\begin{aligned}
E\left[z\left(\widetilde{e}-z^{\prime} b\right)\right] & =0 \\
E\left[R_{0}\left(D_{0}, e_{0}, \widetilde{e},\left(\widetilde{e}-z^{\prime} b\right), w, \gamma, \sigma_{v}\right) \widetilde{e}\right] & =0 \\
E\left[R_{0}\left(D_{0}, e_{0}, \widetilde{e},\left(\widetilde{e}-z^{\prime} b\right), w, \gamma, \sigma_{v}\right)\left(\widetilde{e}-z^{\prime} b\right)\right] & =0 \\
E\left[R_{0}\left(D_{0}, e_{0}, \widetilde{e},\left(\widetilde{e}-z^{\prime} b\right), w, \gamma, \sigma_{v}\right) e_{0}\right] & =0 \\
E\left[R_{1}\left(D_{1}, e_{1}, \widetilde{e},\left(\widetilde{e}-z^{\prime} b\right), w, \gamma, \sigma_{v}\right) \widetilde{e}\right] & =0 \\
E\left[R_{1}\left(D_{1}, e_{1}, \widetilde{e},\left(\widetilde{e}-z^{\prime} b\right), w, \gamma, \sigma_{v}\right)\left(\widetilde{e}-z^{\prime} b\right)\right] & =0 \\
E\left[R_{1}\left(D_{1}, e_{1}, \widetilde{e},\left(\widetilde{e}-z^{\prime} b\right), w, \gamma, \sigma_{v}\right) e_{1}\right] & =0
\end{aligned}
$$

Here, $z$ includes instruments $\bar{e}_{i}^{(t)}$ and $e^{(t-2)}$ corresponding to moment conditions (3) and (4) respectively; under homoscedasticity, additional moment conditions corresponding to (5) may be included.

A GMM estimator based on the above moment conditions is simple to implement. Typically, such a method based on control functions would be applicable only if the endogenous variables are continuous (not limited dependent); the assumption $E(z \varepsilon)=0$ is typically violated otherwise.

\subsubsection{Ordered choice with fixed intervals}

Exogeneity of the censoring intervals may be a tenuous assumption. However, in many applications, the intervals are fixed in repeated sampling. This 
is often because the DGP allows measurement of the response in integer intervals; for example, education or business longevity measured in years, business cycle duration in quarters, income in thousands of currency units, and so on. In this paper, we consider an application to monetary policy decision making, where preferred changes are in multiples of 25 basis points. In all of these examples, the underlying censoring scheme can be characterised by a sequence of $K+1$ intervals

$$
I_{k}=\left[\alpha_{k-1}, \alpha_{k}\right], k=1, \ldots, K+1,
$$

where $\alpha_{0}$ and $\alpha_{K+1}$ may take finite values, or may be set to $-\infty$ and $\infty$ respectively, and the intervals may be considered as open or closed at either threshold depending on the application. In this setup, interval censored data is equivalent to observing a sequence of discrete decision functions $D_{k}$ and the resulting discrete choice variable $D$, where

$$
\begin{aligned}
D_{k} & =1\left(\alpha_{k}+\widetilde{e} w+u \geq 0\right) ; \\
D & =\sum_{k=1}^{K} D_{k} \in\{0,1,2, \ldots, K\} .
\end{aligned}
$$

This is a variant of the usual ordered choice model, with the difference that the interval boundaries are fixed by design and are therefore not required to be estimated. Although the underlying censoring intervals of the latent response variable here clearly depends on $\widetilde{e}$, the censoring scheme itself is exogenous. Lewbel (2000) has developed estimates of the ordered choice model in the case when one of the regressors is "very exogenous". ${ }^{2}$ This may be a strong assumption in many cases, and particularly in the context of our application to monetary policy decision making. ${ }^{3}$

\footnotetext{
${ }^{2}$ Intuitively, a "very exogenous regressor" has three properties. First, it is a regressor in the latent variable model and has coefficient unity. Second, conditional on all other endogenous, exogenous and instrumental variables in the model for the regression errors (6), it is independent of the error term $u$. Third, it has a support large enough to counterbalance the effect of other regressors and the errror. The second condition is similar to exogeneity but stronger - exogeneity requires conditioning only on the exogenous variables in the model. The regressor must also take both positive and negative values, which is easily achieved by location shifts.

${ }^{3}$ Specifically, while preferred changes are observed in multiples of 25 basis points, the assignment of these values to certain intervals is somewhat subjective, and dependent on the pattern of the data. For example, in our application, we assign a larger interval to the status quo position of "no change", partly to reflect the preference for stable interest rates.
} 
Nevertheless, we may cast the censored regression problem as one where $K$ decision functions are sequentially evaluated for each individual. The interval corresponding to each single decision is fixed a priori, in a way that is independent of the regression error $u$. Following Blundell and Smith (1986) and Lewbel (2004), we set up the problem as in (7) earlier.

Then, adapting Lewbel (2004) to our setting, we obtain the moment conditions:

$$
\begin{aligned}
E\left[z\left(\widetilde{e}-z^{\prime} b\right)\right] & =0 \\
E\left[R_{0}\left(D_{1},-\alpha_{1}, \widetilde{e},\left(\widetilde{e}-z^{\prime} b\right), w, \gamma, \sigma_{v}\right)\right] & =0 \\
E\left[R_{0}\left(D_{1},-\alpha_{1}, \widetilde{e},\left(\widetilde{e}-z^{\prime} b\right), w, \gamma, \sigma_{v}\right) \widetilde{e}\right] & =0 \\
E\left[R_{0}\left(D_{1},-\alpha_{1}, \widetilde{e},\left(\widetilde{e}-z^{\prime} b\right), w, \gamma, \sigma_{v}\right)\left(\widetilde{e}-z^{\prime} b\right)\right] & =0 \\
E\left[R_{0}\left(D_{1},-\alpha_{1}, \widetilde{e},\left(\widetilde{e}-z^{\prime} b\right), w, \gamma, \sigma_{v}\right) \alpha_{1}\right] & =0 \\
& \vdots \\
E\left[R_{0}\left(D_{K},-\alpha_{K}, \widetilde{e},\left(\widetilde{e}-z^{\prime} b\right), w, \gamma, \sigma_{v}\right)\right] & =0 \\
E\left[R_{0}\left(D_{K},-\alpha_{K}, \widetilde{e},\left(\widetilde{e}-z^{\prime} b\right), w, \gamma, \sigma_{v}\right) \widetilde{e}\right] & =0 \\
E\left[R_{0}\left(D_{K},-\alpha_{K}, \widetilde{e},\left(\widetilde{e}-z^{\prime} b\right), w, \gamma, \sigma_{v}\right)\left(\widetilde{e}-z^{\prime} b\right)\right] & =0 \\
E\left[R_{0}\left(D_{K},-\alpha_{K}, \widetilde{e},\left(\widetilde{e}-z^{\prime} b\right), w, \gamma, \sigma_{v}\right) \alpha_{K}\right] & =0 .
\end{aligned}
$$

The instruments $z$ are defined as before, based on our moment conditions (3), (4) and (5).

There are two important observations to note. First, all the $K$ individual decisions are applied to each individual. Second, as discussed earlier, the choice of endogenous variables is somewhat limited in this approach. This is particularly important for our application where the endogenous regressors are also interval censored.

We address this problem using an error in variables approach. Specifically, we explicitly model the DGP of the endogenous variables and replace the censored observations with estimates of their expectations conditional on their censoring interval. This way, the measurement errors are mean zero and the error in variables problem here is in no way different from that addressed in the standard instrumental variables literature; see, for example, Wansbeek and Meijer (2001). The effectiveness and validity of these instruments are 
empirical issues specific to each individual application, and can be judged in standard ways under the proposed GMM framework.

A potentially more powerful nonparametric approach to instrumental variables estimation of the censored regression model, under the conditional median assumption median $(\varepsilon \mid z)$ has been proposed in Hong and Tamer (2003). We do not prefer this approach for two reasons. First, estimation is dependent on kernel estimators potentially in high dimensions which is not very convenient. Second, the GMM based approach proposed here can be easily combined with other maximum likelihood, or least squares, or method of moments estimation procedures to obtain efficient two stage or three stage estimators (Newey, 1984). This is particularly useful in the application considered in this paper.

\subsection{Estimation in the presence of unobserved factors}

Pesaran and Tosetti (2007) consider a model where, in addition to spatial or network interaction described by a weights matrix, there are unobserved common factors. Their estimation is based on the common correlated factors approach (Pesaran, 2006) where, in addition to the usual regressors, linear combinations of unobserved factors are approximated by cross section averages of the dependent and explanatory variables. Defining notions on weak and strong cross section dependence, Pesaran and Tosetti (2007) show that the common correlated factors approach provides consistent estimates of the slope coefficient under both forms of dependence. Our interest here is, however, on inference on network interactions under the model

$$
\begin{aligned}
y_{i t} & =\eta_{i}+\alpha_{i}^{\prime} d_{t}+\beta_{i}^{\prime} x_{i t}+\alpha_{i}^{(y)} \bar{y}_{t}+\alpha_{i}^{(x)^{\prime}} \bar{x}_{t}+e_{i t}, \\
e_{t} & =W e_{t}+u_{t}, \quad t=1,2, \ldots, T,
\end{aligned}
$$

where our original underlying model (1) is simply augmented with cross section averages of $y_{i t}$ and $x_{i t}\left(\bar{y}_{t}\right.$ and $\bar{x}_{t}$ respectively).

While inference in Pesaran and Tosetti (2007) assumes certain structural constraints on the weights matrix, our network interactions are unrestricted except for the identifying assumption that the matrix $(I-W)$ is nonsingular. Instead, we achieve identification through the moment conditions given in (3), (4) and (5). Under these moment conditions, GMM estimation is straighforward.

As before, in the case when responses are interval censored, we can proceed by assuming either that the censoring intervals are exogenous, or that 
our ordered choices are made over fixed intervals. In the former case, we use the moment conditions (10) or (12) in the latter.

Thus, our model and methods can easily accommodate unobserved factors in addition to cross section dependence, and the network interactions are practically unrestricted. The implications of this weaker assumption on the weights matrix, as compared with Pesaran and Tosetti (2007), is a matter for further study.

\subsection{Spatial autoregressive model with spatial autore- gressive errors}

Case (1991) and Pinkse et al. (2002), among others, have considered models where there is spatial dynamics in the response variable, in addition to spatial dependence in the errors. Specifically, we consider a model

$$
y_{t}=\eta+W_{1} y_{t}+A d_{t}+\beta^{\prime} X_{t}+e_{t}, \quad t=1,2, \ldots, T
$$

where $y_{t}$ and $e_{t}$ are $N \times 1$ vectors, and $X_{t}$ is a $N \times k$ matrix of regressors, and $\eta$ is the $N \times 1$ vector $\left(\eta_{1}, \eta_{2}, \ldots, \eta_{N}\right)^{\prime}$ of fixed effects, and $d_{t}$ is a $p \times 1$ vector of observed common factors. While cross section dynamics in $y_{t}$ is described by the weights matrix $W_{1}$, dependence in the errors is given by

$$
e_{t}=W_{2} e_{t}+u_{t}
$$

where $W_{2}$ is a different matrix of cross section or network interactions. Our objective is to estimate both $W_{1}$ and $W_{2}$.

Moment conditions corresponding to the errors are as described earlier in (3), (4) and (5). Analogous to the model for $e_{t}$, we can develop moment conditions for dynamics in $y_{t}$. Specifically, the moment conditions based on spatial time lags of $y_{t}$ can be given by

$$
\begin{aligned}
E\left(\bar{y}_{i}^{(t)} \cdot e_{i t}\right) & =0, \quad \bar{y}_{i}^{(t)}=\left(y_{i t}^{(1)}, y_{i t}^{(2)}, \ldots, y_{i t}^{\left(k_{t}\right)}\right) ; \text { and } \\
E\left(y^{(t-2)} \cdot e_{i t}\right) & =0, \quad y^{(t-2)}=\left(y_{1}^{(t-2)}, y_{2}^{(t-2)}, \ldots, y_{N}^{(t-2)}\right), \\
y_{i}^{(t-2)} & =\left(y_{i 1}, y_{i 2}, \ldots, y_{i, t-2}\right), t=3, \ldots, T .
\end{aligned}
$$

We propose a sequential GMM estimation strategy, first estimating (14) under moment conditions (16) and (17), collecting residuals, and then using 
the residuals to estimate (15) under moment conditions (3), (4) and (5). Validity of this sequential method follows from Newey (1984).

Estimation of a similar model with unobserved factors, given by

$$
y_{t}=\eta+W_{1} y_{t}+A d_{t}+\beta^{\prime} X_{t}+\alpha_{(\bar{x})}^{\prime} \bar{x}_{t}+e_{t}, \quad t=1,2, \ldots, T
$$

and (15) follows along exactly similar lines. Note that the unobserved factor model in this case includes only cross sectional averages of $x_{i t}$, since spatial lags of the response variable are already included in the RHS.

In the case where responses are interval censored, the inclusion of common factors can have a special advantage. Since endogeneity in our framework is in the nature of cross section or network dependence, the above approximation for correlated factors have the advantage of averaging out these cross section interactions. Therefore, the assumption of "very exogenous regressors" is more plausible here. Following Lewbel (2000), we outline below the moment conditions required for implementation of a GMM estimation procedure, under the assumption of ordered choice with fixed intervals. However, while Lewbel (2000) uses a nonparametric estimator for the conditional density of the "very exogenous regressor" given other regressors and instruments, we follow Lewbel (2004) in assuming a linear dependence structure and normal errors. Therefore, we assume the model:

$$
\begin{aligned}
& S=\left(x_{1}^{\prime}, z^{\prime}\right)^{\prime} ; \bar{x}=S^{\prime} b_{v}+v \\
& v \perp S, u ; v \sim N\left(0, \sigma_{v}^{2}\right),
\end{aligned}
$$

where the cross section averaged regressor $\bar{x}$ is assumed to be scalar (for simplicity) and "very exogenous" (which is ensured by the (19) conditions), $x_{1}$ denotes the collection of all other regressors (comprising endogenous spatial lags of the dependent variable, observed common factors and censoring thresholds), and $z$ denotes instruments $\bar{y}_{i}^{(t)}$ and $y^{(t-2)}$. Analogous to (11), we have a sequence of discrete decision functions $D_{k}$ and the resulting discrete choice variable $D$, where

$$
\begin{aligned}
D_{k} & =1\left(\frac{\alpha_{k}}{\alpha_{(\bar{x})}}+\frac{1}{\alpha_{(\bar{x})}} x_{1}^{\prime} \beta_{1}+\bar{x}+\frac{1}{\alpha_{(\bar{x})}} u \geq 0\right) ; \\
D & =\sum_{k=1}^{K} D_{k} \in\{0,1,2, \ldots, K\} .
\end{aligned}
$$


Note that the coefficient on the "very exogenous regressor" $\bar{x}$ is scaled to unity. This, however, is not a constraint, since the threshold $\alpha_{k}$ is included as one of the regressors, and the proper scale can be recovered from its coefficient $\alpha^{*}=\frac{1}{\alpha_{(\bar{x})}}$. Then, using Theorem 1 of Lewbel (2000) and the model (19), we obtain the following moment conditions:

$$
\begin{aligned}
E\left[S\left(\bar{x}-S^{\prime} b_{v}\right)\right] & =0 \\
E\left[\sigma_{v}^{2}-\left(\bar{x}-S^{\prime} b_{v}\right)^{2}\right] & =0 \\
E\left[z\left\{\left[D_{1}-1(\bar{x} \geq 0)\right]\left(2 \pi \sigma_{v}^{2}\right)^{-1 / 2} \exp \left[\frac{\left(\bar{x}-S^{\prime} b_{v}\right)^{2}}{2 \sigma_{v}^{2}}\right]\right\}\right] & =0 \\
-\alpha^{*}\left(\alpha_{1}+x_{1}^{\prime} \beta_{1}\right) & \vdots \\
E\left[z\left\{\left[D_{K}-1(\bar{x} \geq 0)\right]\left(2 \pi \sigma_{v}^{2}\right)^{-1 / 2} \exp \left[\frac{\left(\bar{x}-S^{\prime} b_{v}\right)^{2}}{2 \sigma_{v}^{2}}\right]\right\}\right] & \vdots \\
-\alpha^{*}\left(\alpha_{K}+x_{1}^{\prime} \beta_{1}\right) & 0 .
\end{aligned}
$$

As earlier, estimation under the above moment conditions is standard. The advantage of being able to use almost any kind of instruments comes at the cost of the stronger assumption of "very exogenous regressor". Because of the structure of the problem here, all the parameters are free and recoverable, including the coefficient on $\bar{x}$ and the error variance $\sigma_{v}^{2}$. Further, in principle, multiple "very exogenous regressors" may be available. This has the potential advantage of enhancing efficiency of the estimation procedure. In this case, however, tail assumptions as in Magnac and Maurin (2008) will be required. Once the main model (18) has been estimated, the residuals are used to estimate the interaction model (15) for the errors using moment conditions (10) or (12). Finally, moment conditions for both the main model (18) and the model (15) for the errors can be combined together for joint GMM estimation. This implies using a much larger set of moment conditions than the sequential approach, which we prefer.

\subsection{Inferring on network structure}

The GMM estimation framework adopted in this paper relies crucially on the validity and adequacy of the assumed moment conditions. The issues related to this are well understood in the literature; see, for example, Hall (2004). 
Throughout our empirical exercise, we test for overidentifying restrictions using the standard Sargan-Hansen $J$-statistic (Hansen, 1982).

The more interesting tests in our setup relate to network structure. To emphasize, our main philosophy in this paper was that interactions in social networks and committees are endogenous outcomes of strategic behaviour of agents. This is in sharp contrast to the view in the spatial econometrics literature where interaction weights are fixed by design, known at least approximately, and have no special informational content beyond accounting for cross section dependence in the underlying economic model. We, however, conduct inference on the weights matrix specifically to understand the strength (and nature) of interactions, and to study the pattern of links evolving from network interactions by economic agents.

Recent literature on network theory (see, for example, Goyal $(2005,2007)$, Goyal and Vega-Redondo (2007) and references therein) point to a variety of equilibrium network structures arising from rational agents' bargaining strategies, and crucially depend on payoffs and incentives. Theory suggests that certain simple network architectures, such as star or cycle, may emerge as equilibrium solutions, while structures such as hybrid cycle-star may be less stable. Further, there are important roles for asymmetric networks.

In our framework, evaluating that the network structure has a particular simple architecture reduces to testing for simple parameter restrictions in the interaction weights. Various such tests have been proposed within the GMM framework, and issues relating to testing are well studied; see, among others, Newey and West (1987), Bond et al. (2001), Hall (2004) and Kleibergen (2007). We suggest the LR type test for the purpose of evaluating network structures and use this in our analysis in this paper.

\section{Application}

We develop the methodological approach described above in the context of a particular form of interaction. In this case it is the decisions that a Committee makes on interest rates for the conduct of monetary policy. [ADD bits on MPC] 


\section{A Model of a MPC}

A standard way of understanding how a committee comes to a decision is that each member reacts independently to a 'signal' coming from the economy and makes an appropriate decision in the light of this signal and the particular preferences/expertise of the member. A voting method then generates a decision that is implemented. In practice there is also various forms of cross committee dependence. Before a decision is made there is a shared discussion of the state of the world as seen by each of the members. In this section we model the possible interactions between members of a committee as one in which interaction occurs in the form of deliberation. Views are exchanged about the interpretation of signals and an individual member may decide to revise his view depending upon how much weight he places on his own and the views of others.

This process can be cast as a simple signal extraction problem within a highly stylised framework. Let the $j$-th MPC member formulate an (unbiased) estimate of the output gap, $y_{t}^{j}$. Then the underlying model for each member is:

$y_{t}^{j}=\beta_{j} \cdot x_{t}^{j}+\omega_{t}^{j}$ with $\omega_{t}^{j} \backsim N\left(0, \sigma_{\omega^{j}}^{2}\right)$ and $E\left(y_{t}^{j}\right)=\beta_{j} \cdot x_{t}^{j}=y_{t}$, for $j=1, . . m$.

The internal process of deliberation between the members of the Committee reveals to everyone individual views of the output gap brought to the meeting ${ }^{4}$. The $j$-th member then optimally combines his estimate with the estimates of the others, attaching a weight to each. This weight depends on the $j$-th member's (subjective) evaluation of the usefulness of the forecasts of others. For example the $j$-th member's view of the (unbiased) estimate of the output gap of the $k$-th member is:

$$
y_{t}^{j k}=y_{t}+\omega_{t}^{j k} \text { with } \omega_{t}^{j k} \backsim N\left(0, \sigma_{j k}^{2}\right) \text {, for } j=1, . . m \text {. }
$$

A diffuse prior, $\sigma_{j k}^{2}$, in the bayesian sense, suggests little confidence in the forecast of the $k$-th member's estimate relative to the estimate of the $j$-th

\footnotetext{
${ }^{4}$ Austin-Smith and Banks (1996) point out that we need each committee member to be open in revealing his estimate of the output gap and sincere in casting a vote for an interest rate decision that corresponds to the infomation available. Although we consider only the one period problem here, in a multi-period context we assume that reputational considerations are sufficiently powerful to ensure fair play.
} 
member himself and the estimates of the rest of the committee. The updated (and optimal in the mean squared error sense) estimate of the output gap for the $j$-th member is then a weighted average (with the weights summing to one) of the $m$ members.

$$
y_{t}^{j}=\mathbf{w}_{j}^{\prime} \mathbf{y}_{t}, \text { for } j=1, . . m .
$$

where $\mathbf{y}_{t}$ is a $m \times 1$ vector of estimates of $y$ and $\mathbf{w}_{j}$ is a $m \times 1$ vector of weights (that sum to one) given by ${ }^{5}$ :

$$
\mathbf{w}^{j}=\mathbf{e}^{\prime} \mathbf{S}_{j}^{-1} / \mathbf{e}^{\prime} \mathbf{S}_{j}^{-1} \mathbf{e}, \text { for } j=1, . . m .
$$

Here, $\mathbf{e}$ is a $m \times 1$ unit vector and $\mathbf{S}_{j}$ is defined as the matrix:

$$
\mathbf{S}_{j}=\left[\begin{array}{ccccc}
\sigma_{j 11}^{2} & \sigma_{j 12} & \cdot & \cdot & \sigma_{j 1 m} \\
\sigma_{j 21} & \sigma_{j 22}^{2} & & & \cdot \\
\cdot & & \cdot & & \cdot \\
\cdot & & & \cdot & \\
& & & \cdot & \\
\sigma_{j m 1} & \cdot & \cdot & & \sigma_{j m m}^{2}
\end{array}\right], \text { for } j=1, . . m .
$$

The weights that members attach to the estimate of the output gap can in principle be negative if there is a sufficiently large negative covariance, or larger than one if there is a large positive covariance. Deliberation then implies a revised $1 \times m$ vector of estimates of the output gap: $\mathbf{y}_{t}^{r}=\left(y_{t}^{1}, y_{t}^{2}, \ldots y_{t}^{m}\right)^{\prime}$. This vector in turn maps into an interest decision through:

$$
i_{j t}=\left(\pi_{t \mid t}-\pi^{*}\right)+\frac{1}{\alpha_{j} \beta_{2 j}} \pi_{t+1 \mid t}+\frac{\beta_{1}}{\beta_{2 j}} y_{t \mid t}^{j}+\varsigma_{j t} \quad \text { for } j=1, \ldots, m,
$$

where $\pi^{*}$ is the inflation target, $\pi_{t+1 \mid t}$ the forecast of inflation at time period $t+1$ based on information available in period $t$, and likewise for $\pi_{t \mid t}$ and $y_{t \mid t}^{j}$, and the subscript $t \mid t$ indicates that current realisations of the output gap

\footnotetext{
${ }^{5}$ This is of course the standard formula for the optimal combination of linear signals and was first introduced into economics by Bates and Granger (1969) as a way of combining forecasts.
} 
and inflation may well be imperfectly observed, and need to be forecasted. ${ }^{6}$ Therefore, the $1 \times m$ vector, $\mathbf{i}_{t}$ of decisions about the setting of the interest rate is a linear mapping from $\mathbf{y}_{t}^{r}$ to $\mathbf{i}_{t}$. The actual interest setting is then the median of $\mathbf{i}_{t}$, median $\left(\mathbf{i}_{t}\right)$.

The revised estimate of the output gap after the initial stage of deliberation could be subject to further revision if there is an opportunity for members to inform the rest of the committee of the change in their views. This would in turn involve a revision of the vector of estimates to reflect the new information that has been revealed by further deliberation. Iteratively, a stage would be reached when no further changes would be made to the estimate of the $j$-th member. However, in this case under reasonable assumptions this will converge to a position in which all members have the same belief about the output gap. ${ }^{7}$ To show this the interaction matrix obtained by stacking the row matrices of optimal weights - is:

$$
\boldsymbol{W}=\left[\begin{array}{cccc}
w_{11} & w_{12} & \ldots & w_{1 m} \\
w_{21} & w_{22} & \ldots & w_{2 m} \\
\vdots & \vdots & \ddots & \vdots \\
w_{m 1} & w_{m 2} & \ldots & w_{m m}
\end{array}\right]
$$

and if $\mathbf{y}_{t}^{k}$ is a $m \times 1$ vector of estimates of $y$ with which each member of the Committee enters the meeting, then after deliberation we have

$$
\mathbf{y}_{t}^{k+1}=\mathbf{W} \mathbf{y}_{t}^{k}
$$

where $\mathbf{y}_{t}^{k+1}$ is a $1 \times m$ vector of revised estimates of the output gap after deliberation.

\subsection{Interactions among members of the Committee}

Covariances between forecast errors imply interactions between members over and above the sharing during deliberation of individual estimates of the output gap. ${ }^{8}$ One form of interaction may involve strategic voting by a sub-group

\footnotetext{
${ }^{6}$ The derivation of the above inflation 'feed forward' rule (25) is based on Svensson (1997), where the policymaker only targets inflation, and the central bank can (in expectation) use the current interest rate to hit the target for inflation two periods hence; for further details, see Bhattacharjee and Holly (2008).

${ }^{7}$ Instead we assume that there is only a single revision to the estimate of the output gap as a result of deliberation.

${ }^{8}$ The pooling of information avoids any of the complications that arise in Townsend's (1983) model of 'forecasting the forecasts of others'.
} 
of the Committee seeking to influence the interest rate decision. ${ }^{9}$ However, it is well known that when the median is used to determine an outcome it will be invariant to attempts to act strategically.

However, it is possible that there are commonalities among members of a committee that can be thought of as a form of likemindedness. Some members share a common background or experiences and happen to share a common view of the world. In this case there will be positive covariances between the forecast errors of groups of members who share common views. Similarly, there may be conflicts between preferences of other members. The current literature on political economy emphasizes several channels through which significant interactions may arise; see Gerling et al. (2005) for further discussion..

Grüner and Kiel (2004) analyze collective decision problems in which individual bliss points are correlated but not identical. Like our setup here, all agents obtain private information about their most desired policy, but the individually preferred decision of a group member does not only depend on his own private information but also on the other group members' private information. They find that for weak interdependencies, the equilibrium strategy under the median mechanism is close to truth-telling whereas the mean mechanism leads to strong exaggeration of private information. This is similar to our arguments here. However, in a setting with interdependencies, pre-vote communication may affect equilibrium behavior - an issue not yet addressed clearly in the literature. Our analysis in this paper suggests that limits to information sharing (only a single revision in our case) may reflect interdependencies, both positive and negative, in the final votes though not necessarily in the median outcome.

Matsen and Røisland (2005) highlight tha fact that members in a MPC may represent different constituents (countries or regions, sectors etc.) with potentially different effects of interest rate changes. Such asymmetric shocks and transmission mechanisms can induce corresponding members to engage in strategic voting. In this case, there may be positive or negative interactions originating from unobserved factors which are specific to sub-groups within the MPC. This is similar to the likemindedness view discussed above.

Li et al. (2001) analyze small-committee decisions when members have partially conflicting interests and possess private information, but preferences

\footnotetext{
${ }^{9}$ As before we assume openness and sincerity in providing information about what the output is.
} 
are common knowledge. Their main finding is that information cannot be fully shared and voting procedures arise as the equilibrium method of information aggregation. Further, in a recent contribution, Felgenhauer and Grüner (2008) show that transparency in publishing voting behaviour may have unintended consequences in settings where external influence is high. Specifically, benefits from strategic voting increase in this case, not only for the pivotal voters, but also extreme hawks or doves.

Recent literature on endogenous network formation also point to important roles for strategic information sharing and links (Goyal, 2007). First, transmission of information may be unidirectional or bidirectional. Granovetter (1973) interprets unidirectional transmission as a weak link and bidirectional as a strong link. Second, quality of links may vary quite a lot, and network formation endogenously depends on the quality (Goyal, 2005). Third, ceratin forms of network architecture often emerge as equilibrium solutions, while others are not stable. For example, a periphery-sponsored star is a Nash equilibrium in Goyal (2005), while under capacity constraints Goyal and Vega-Redondo (2007) find a cycle network more meaningful. In the context of interactions between MPC members, this suggests two important aspects. First, a network where all members place high effort to obtain private information from others is often not an equilibrium solution. Second, the architecture of networks which emerge in equilibrium are useful to understand the nature of information aggregation and constraints. Our framework for inference on cross member interactions within the MPC will inform on both these aspects.

Finally, within a MPC setting, Sibert $(2002,2003)$ points to the important role for reputational effects and strategic behaviour. Specifically, she shows that behavviour of new members may be different from veterrans, and this difference can depend on the balance of power and size of the committee. Since, under transparency, voting behaviour is the main signal for reputational effects, this line of research also has potential implications for our model of MPC interactions.

\section{$5 \quad$ Data and Empirical Model}

In the previous section we presented a model of committee decision making based on an inflation forecast rule and accommodating heterogeneity across policy makers and interaction between their individual decisions. In 
this section we turn to an empirical examination of decision making within the Monetary Policy Committee of the Bank of England. In the following subsections, we present our data and the empirical model, and discuss the econometric methods used to estimate the model.

\subsection{Data and sample period}

The primary objectives of the empirical study is to understand cross member interaction in decision making at the Bank of England's MPC, within the context of the model of committee decision making presented in the previous section. Importantly, our framework allows for heterogeneity among the MPC members and the limited dependent nature of preferred interest rate decisions. Our dependent variables are the decisions of the individual members of the MPC. The source for these data are the minutes of the MPC meetings.

TABLE 1: Voting records of selected MPC members

\begin{tabular}{|l|c|c|c|c|c|c|c|}
\hline \multirow{2}{*}{ Member } & \multirow{2}{*}{ Meetings } & \multicolumn{3}{|c|}{ Votes } & \multicolumn{3}{|c|}{ Dissent } \\
\cline { 3 - 8 } & & Lower & No change & Raise & Total & High & Low \\
\hline Buiter & 36 & 10 & 10 & 16 & 17 & 9 & 8 \\
Clementi & 63 & 14 & 39 & 10 & 4 & 3 & 1 \\
George & 74 & 15 & 51 & 6 & 0 & 0 & 0 \\
Julius & 45 & 18 & 25 & 2 & 14 & 0 & 14 \\
King & 85 & 14 & 50 & 21 & 12 & 12 & 0 \\
\hline \hline
\end{tabular}

Since mid-1997, when data on the votes of individual members started being made publicly available, the MPC has met once a month to decide on the base rate for the next month. ${ }^{10}$ Over most of this period, the MPC has had 9 members at any time: the Governor (of the Bank of England), 4 internal members (senior staff at the Bank of England) and 4 external members. External members were usually appointed for a period ranging from 3 to 4 years. Because of changes in the external members, the composition of the MPC has changed reasonably frequently. To facilitate study of heterogeneity and interaction within the MPC, we focus on 5 selected members, including the Governor, 2 internal and 2 external members. The longest such period when the same 5 members have concurrently served in the MPC is the 33

\footnotetext{
${ }^{10}$ The MPC met twice in September 2001. The special meeting was called after the events of $09 / 11$.
} 
month period from September 1997 to May 2000. The 5 MPC members who served during this period are: George (the Governor), Clementi and King (the 2 internal members) and Buiter and Julius (the 2 external members). The voting pattern of these selected MPC members suggest substantial variation (Table 1). ${ }^{11}$

In order to explain the observed votes of the 5 selected members, we collected information on the kinds of data that the MPC looked at for each monthly meeting. The important issue was to ensure that we conditioned only on what information was actually available at the time of each meeting. Assessing monetary policy decisions in the presence of uncertainty about forecast levels of inflation and the output gap (including uncertainty both in forecast output levels and perception about potential output) requires collection of real-time data available to the policymakers when interest rate decisions are made as well as measures of forecast uncertainty. This contrasts with many studies of monetary policy which are based on realised (and subsequently revised) measures of economic activity (see Orphanides, 2003).

We collected information on unemployment (where this typically refers to unemployment three months prior to the MPC meeting), as well data on the underlying state of asset markets (housing prices, share prices and exchange rates). We measure unemployment by the year-on-year change in International Labor Organization (ILO) rate of unemployment, lagged 3 months. The ILO rate of unemployment is computed using 3 months rolling average estimates of the number of ILO-unemployed persons and size of labour force (ILO definition), both collected from the Office of National Statistics (ONS) Labour Force Survey. Housing prices are measured by the year-on-year growth rates of the Nationwide housing prices index (seasonally adjusted) for the previous month (Source: Nationwide). Share prices and exchange rates are measured by the year-on-year growth rate of the FTSE 100 share index and the effective exchange rate respectively at the end of the previous month (Source: Bank of England). The other current information included in the model is the current level of inflation - measured by the

\footnotetext{
${ }^{11}$ For example, of the 45 meetings which Julius attended, the votes for 14 were against the consensus decision, and all of these were for a lower interest rate. On the other hand, King disagreed with the consensus decision in 12 of the 82 meetings he attended, voting for a higher interest rate each time. Buiter dissented in 17 meetings out of 36, voting on 8 occasions for a lower interest rate and 9 times in favour of a higher one. See also King (2002) and Gerlach-Kristen (2004).
} 
year-on-year growth rate of RPIX inflation lagged 2 months (Source: ONS).

Our model also includes expected rates of future inflation and forecasts of current and future output. One difficulty with using the Bank's forecasts of inflation is that they are not sufficiently informative. By definition, the Bank targets inflation over a two year horizon, so it always publishes a forecast in which (in expectation) inflation hits the target in two years time. To do anything else would be internally inconsistent. Instead, as a measure of future inflation, we use the 4 year ahead inflation expectations implicit in bond markets at the time of the MPC meeting, data on which can be inferred from the Bank of England's forward yield curve estimates obtained from index linked bonds. ${ }^{12}$ For current output, we use annual growth of 2month-lagged monthly GDP published by the National Institute of Economic and Social Research (NIESR) and for one-year-ahead forecast GDP growth, we use the Bank of England's model based mean quarterly forecasts.

Finally, uncertainty in future macroeconomic environment and private perceptions about the importance of such uncertainty plays an important role in the model developed in this paper. The extent to which there is uncertainty about the forecast of the Bank of England can be inferred from the fan charts published in the Inflation Report. As a measure of uncertainty in the future macroeconomic environment, we use the standard deviation of the one-year-ahead forecast. These measures are obtained from the Bank of England's fan charts of output; details regarding these measures are discussed elsewhere (Britton et al., 1998). The forecasts of one-year-ahead output growth and its variance show substantial variation over time (Figure 1).

\subsection{The empirical model}

We start with the model of individual voting behaviour within the MPC developed in the previous section (25). The model includes individual specific heterogeneity in the fixed effects, in the coefficients of inflation and output gap, and in the effect of uncertainty. We aim to estimate this model in a form where the dependent variable is the $j$-th member's preferred change in the (base) interest rate. In other words, our dependent variable, $v_{j t}$, represents the deviation of the preferred interest rate for the $j$-th member

\footnotetext{
${ }^{12}$ We use the four year expected inflation figure because the two year figure is not available for the entire sample period. In practice the inflation yield curve tends to be very flat after two years.
} 


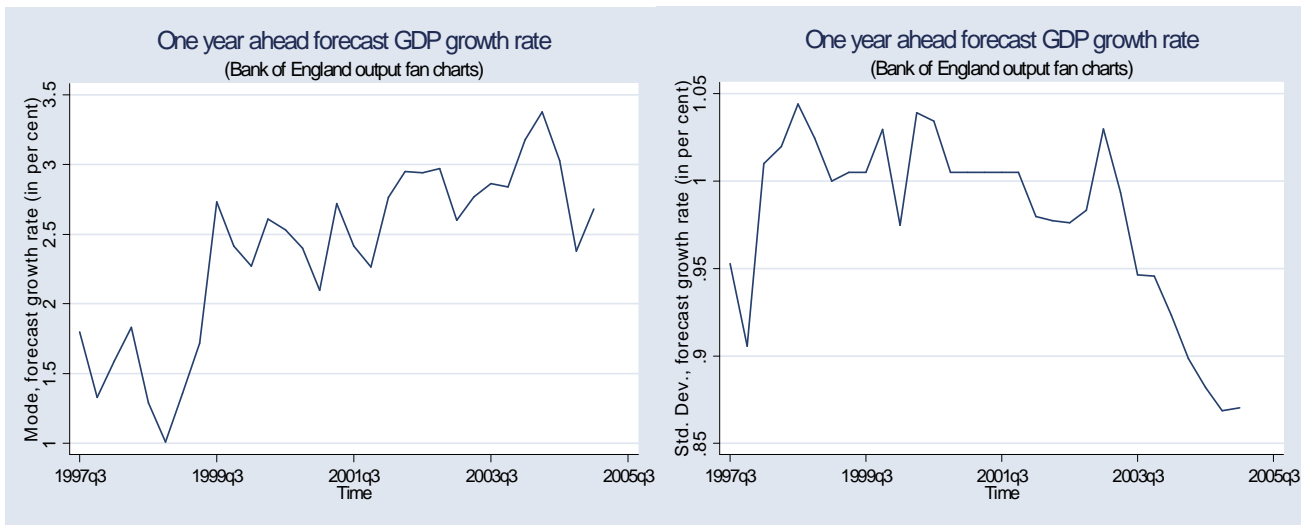

Figure 1: Variation in forecast output growth and its variance over time

(at the meeting in month $t$ ) from the current (base) rate of interest $r_{t-1}$ :

$$
v_{j t}=i_{j t}-r_{t-1} \text {. }
$$

Therefore, we estimate the following empirical model of individual decision making within the MPC:

$$
\begin{aligned}
v_{j t}= & \phi_{j}+\beta_{j}^{(r)} \cdot \Delta r_{t-1}+\beta_{j}^{(\pi 0)} \cdot \pi_{t}+\beta_{j}^{(\pi 4)} \cdot \pi_{t+4 \mid t}+\beta_{j}^{(y 0)} \cdot y_{t \mid t} \\
& +\beta_{j}^{(y 1)} \cdot y_{t+1 \mid t}+\beta_{j}^{(\sigma)} \cdot \sigma\left(y_{t+1 \mid t}\right)+\underline{\lambda}_{j}^{\prime} \cdot \underline{Z}_{t}+e_{j t},
\end{aligned}
$$

where $\underline{Z}_{t}$ represents current observations on unemployment $\left(\triangle u_{t}\right)$ and the underlying state of asset markets: housing, equity and the foreign exchange market $\left(P_{h s g, t}, P_{F T S E, t}\right.$ and $P_{\text {exch,t }}$ respectively). This is combined with a model for interaction between the error terms for different members

$$
e_{t}=W e_{t}+u_{t}
$$

where $W$ is a $(N \times N)$ matrix of interaction weights with zero diagonal elements and unrestricted entries on the off-diagonals, such that $(I-W)$ is non-singular. Standard deviation of the one-year ahead forecast of output growth is denoted by $\sigma\left(y_{t+1 \mid t}\right)$; this term is included to incorporate the notion that the stance of monetary policy may depend on the uncertainty relating to forecast future levels of output and inflation. As discussed in the previous section, increased uncertainty about the current state of the 
economy will tend to bias policy towards caution in changing interest rates. In particular, this strand of the literature suggests that optimal monetary policy may be more cautious (rather than activist) under greater uncertainty in the forecast or real-time estimates of output gap and inflation (see Issing, 2002; Aoki, 2003; and Orphanides, 2003). Since, as previously discussed, the published inflation forecast is not sufficiently informative, we confined ourselves to uncertainty relating to forecasts of future output growth.

However, there are two important additional features of our data generating process that render the estimation exercise nonstandard. First, the dependent variable is observed in the form of votes, which are highly clustered interval censored outcomes based on the underlying decision rules. Second, the regression errors are interrelated across the members.

\subsubsection{Interval censored votes}

Votes of MPC members are highly clustered, with a majority of the votes proposing no change in the base rate. The final decisions on interest rate changes are all similarly clustered. For the Bank of England's MPC as a whole over the period June 1997 to March 2005, 69 per cent of the meetings decided to keep the base rate at its current level, 14 per cent recommended a rise of 25 basis points, 13 per cent recommended a reduction of 25 basis points, and 4 per cent a reduction of 50 basis points.

This clustering has to be taken into account when studying individual votes and committee decisions of the MPC. We do not observe changes in interest rates on a continuous or unrestricted scale, we have a non-continuous or limited dependent variable. Moreover, changes in interest rates are in multiples of 25 basis points. Therefore, following Bhattacharjee and Holly (2005), we use an interval regression framework for analysis; other authors have used other limited dependent variable frameworks, like the logit/ probit or multinomial logit/ probit framework to analyse monetary policy decisions (for recent contributions, see Chevapatrakul et al., 2001, and Gascoigne and Turner, 2003). Our choice of model is based on the need to use all the information that is available when monetary policy decisions are made, as well as problems relating to model specification and interpretation of multinomial logit models (Greene, 1993). We also explored an ordered and multinomial logit formulations, and found the broad empirical conclusions to be similar.

Therefore, the observed dependent variable in our case, $v_{j t, o b s}$, is the truncated version of the latent policy response variable of the $j$-th member, $v_{j t}$, 
which we model as

$$
\begin{aligned}
v_{j t, o b s} & =-0.25 \quad \text { if } \quad v_{j t} \in[-0.375,-0.20) \\
& =0 \quad \text { if } \quad v_{j t} \in[-0.20,0.20] \\
& =0.25 \quad \text { if } \quad v_{j t} \in(0.20,0.375], \text { and } \\
v_{j t} & \in\left(v_{j t, o b s}-0.125, v_{j t, o b s}+0.125\right] \text { whenever }\left|v_{j t, o b s}\right|>0.325
\end{aligned}
$$

The wider truncation interval when there is a vote for no change in interest rates ( $i e$. , for $v_{j t, o b s}=0$ ) may be interpreted as reflecting the conservative stance of monetary policy under uncertainty with a bias in favour of leaving interest rates unchanged.

\subsubsection{Estimation}

Under the maintained assumptions that (a) regression errors are uncorrelated across meetings, and (b) the response variable is interval censored, estimation of the policy reaction function for each member (28) is an application of interval regression (Amemiya, 1973). In our case, however, we have an additional feature that the errors are potentially correlated across members. If we can estimate the covariance matrix of these residuals, then we can use a standard GLS procedure by transforming both the dependent variable and the regressors by premultiplying with the symmetric square root of this covariance matrix. However, the dependent variable is interval censored and has to be placed at its conditional expectation given current parameter estimates and its censoring interval. This sets the stage for the next round of iteration. Now, the dependent variable is no longer censored; hence, a standard SURE methodology can be applied.

Estimating the covariance matrix at the outset is also nonstandard. Because the response variable is interval censored the residuals also exhibit similar limited dependence. ${ }^{13}$ We propose estimation using the ExpectationMaximisation algorithm (Dempster et al., 1977; McLachlan and Krishnan,

\footnotetext{
${ }^{13}$ For example, suppose the observed response for the $j$-th member in a given month $t$ is 0.25 . By our assumed censoring mechanism (30), this response is assigned to the interval $(0.20,0.375]$. Suppose also that the linear prediction of the policy response, based on estimates of the interval regression model is $\widehat{v}_{j t}=0.22$. Then the residual $v_{j t}-\widehat{v}_{j t}$ cannot be assigned a single numerical value, but can be assigned to the interval $(0.20-0.22,0.375-0.22]$. In other words, the residual is interval censored: $v_{j t}-\widehat{v}_{j t} \in(-0.02,0.155]$.
} 
1997). At the outset, we estimate the model using standard interval estimation separately for each member and collect residuals. We invoke the Expectation step of the EM algorithm and obtain expected values of the residuals given that they lie in the respective intervals. Since we focus on five MPC members, for each monthly meeting, we have to obtain conditional expectations by integrating the pdf of the 5 -variate normal distribution with the given estimated covariance matrix.

Iterating the above method till convergence provides us maximum likelihood estimates of the policy reaction function for each of the five members, under standard assumptions, specifically multivariate normality of the cross member errors. The covariance matrix of the errors is unrestricted.

Once the above model is estimated, we obtain interval censored residuals using the initial censoring scheme. These are also placed at their expected values, conditional on estimates of the model parameters and their own censoring interval. Similarly, policy reaction functions are estimated for other members who were in the committee in each month under study, for use as instruments. These are also placed at their conditional expected values. The stage is now set for estimating the matrix of cross member network interactions. This is achieved by GMM, assuming that the censoring intervals are exogenous in the interaction model for the errors, and using moment conditions given in (10). We do not impose homoscedasticity conditions on the idiosyncratic errors in (29) and do not use the corresponding moment condition (5). The validity of the assumed moment conditions is checked using the Sargan-Hansen $J$-test for overidentifying restrictions (Hansen, 1982). This completes a description of our estimation procedure.

For inference on network structures, we follow a similar procedure under parameter restrictions implied by the network architecture. This is implemented in the same way as above. Testing is conducted using the LR type procedure (Newey and West, 1987; also discussed in Hall, 2004).

\section{Results}

We present estimates only for the network interactions in our model for the regression error terms (29). Estimates of the policy reaction function for the members are very similar to Bhattacharjee and Holly $(2005,2008)$ and not discussed here. Similar to the previous papers, we find evidence of substantial heterogeneity in the estimated policy rules. This indicates that monetary 
policy decision making within a committee is more complicated than what can be inferred from an analysis of simple aggregate decisions undertaken in the literature.

Further, as in Bhattacharjee and Holly (2008), the error correlations across members is very large, implying therefore that there is substantial interaction between the decision making processes of the members. This interaction is over and above what can be explained by the rather extensive set of explanatory variables included in our empirical model of individual decision making (28). We estimate the interaction weights by GMM, under the exogenous censoring interval assumption, and using instruments derived from residuals for other members in the committee and lagged residuals of members included in the analysis (from lag 2 backwards). In the spirit of dynamic panel GMM estimators (Arellano and Bond, 1991; Blundell and Bond, 1998), the instrument set is therefore different for each month under analysis. The endogenous error models for each member are estimated separately, though the entire estimation exercise can be combined together within an unified GMM setup. The estimated interaction matrix is presented in Table 2 .

Table 2: Estimated Cross Member Network Interaction Matrix

\begin{tabular}{|c|c|c|c|c|c|c|c|}
\hline & George & Clementi & King & Buiter & Julius & Row SS & $J$-stat. \\
\hline George & 0 & $\begin{array}{c}0.813^{* *} \\
(0.031)\end{array}$ & $\begin{array}{c}0.184^{* *} \\
(0.057)\end{array}$ & $\begin{array}{c}-0.008 \\
(0.061)\end{array}$ & $\begin{array}{c}-0.149^{*} \\
(0.061)\end{array}$ & 0.717 & $\begin{array}{c}9.09 \\
(p=0.77)\end{array}$ \\
\hline Clementi & $\begin{array}{c}0.911^{* *} \\
(0.061)\end{array}$ & 0 & $\begin{array}{c}-0.081 \\
(0.073)\end{array}$ & $\begin{array}{c}0.173^{* *} \\
(0.055)\end{array}$ & $\begin{array}{c}0.159^{* *} \\
(0.057)\end{array}$ & 0.892 & $\begin{array}{l}10.12 \\
(p=0.68)\end{array}$ \\
\hline King & $\begin{array}{c}0.532^{* *} \\
(0.172)\end{array}$ & $\begin{array}{c}-0.283 \\
(0.216)\end{array}$ & 0 & $\begin{array}{c}0.610^{* *} \\
(0.127)\end{array}$ & $\begin{array}{c}0.540^{* *} \\
(0.120)\end{array}$ & 1.027 & $\begin{array}{c}7.67 \\
(p=0.86)\end{array}$ \\
\hline Buiter & $\begin{array}{c}-0.153 \\
(0.277)\end{array}$ & $\begin{array}{l}0.352 \\
(0.233)\end{array}$ & $\begin{array}{c}0.680^{* *} \\
(0.132)\end{array}$ & 0 & $\begin{array}{c}-0.454^{* *} \\
(0.067)\end{array}$ & 0.816 & $\begin{array}{c}11.36 \\
(p=0.58)\end{array}$ \\
\hline Julius & $\begin{array}{c}-0.427^{* *} \\
(0.086)\end{array}$ & $\begin{array}{c}0.481^{* *} \\
(0.121)\end{array}$ & $\begin{array}{c}0.501^{* *} \\
(0.072)\end{array}$ & $\begin{array}{c}-0.340^{* *} \\
(0.085)\end{array}$ & 0 & 0.780 & $\begin{array}{c}10.92 \\
(p=0.62)\end{array}$ \\
\hline
\end{tabular}

${ }^{* *},{ }^{*}$ and ${ }^{+}-$Significant at $1 \%, 5 \%$ and $10 \%$ level respectively.

HAC standard errors in parentheses.

The moment conditions are validated by the Sargan-Hansen $J$-test (Hansen, 1982) for each equation. Several important observations can be drawn from the estimates. First, while most (though not all) of the significant links between members are strong (that is, they run both ways), the interaction weights matrix is far from symmetric. While Buiter affects the decisions of 
Clementi significantly, the opposite is not true. Asymmetry is most obvious for the strong influences running from George to King and Julius, while interactions in the opposite direction (though significant) are not as large. Second, some network weights are not significant either way. Specific examples are between George and Buiter, and between Clementi and King. This points to important constraints on information sharing within the committee. Third, some interaction weights are negative. Prominent examples are between Julius on the one hand and George and Buiter on the other. At the same time, a graphical representation of the network structure (Figure 2) clearly shows that most of the interactions within these members involve Julius; in other words, she is most centrally located. Fourth, and perhaps unsurprisingly, the internal members are more influential within the committee, and George (the Governor) is the most influential of all. Here, we measure influence by the sum of squares of significant network weights connecting to a member. Sixth, contrary to what is predicted in theoretical models of networks, neither the star network nor a cycle have emerged as the network architecture here. This was formally tested using a LR test, which rejected the null of a star network (and a cycle network) at the $1 \%$ level of significance.

The above observations point to the usefulness of the methods proposed in this paper. They also point to important insttutional observations which may be important in developing political economy and network theories of interactions within a monetary policy committee in the first instance, and also possibly within committees in general.

Finally, the estimates are numerically, and definitely in sign, similar to estimates of spatial weights reported in Bhattacharjee and Holly (2008). In the other paper, the weights were estimated using certain structural restrictions on the weights matrix, using methodology developed in Bhattacharjee and Jensen-Butler (2005). ${ }^{14}$ At the same time, significance of some of the weights are different. Admittedly, such structural restrictions on the weights matrix can be quite strong and violated in empirical applications. This observation further underscores the usefulness of the methods proposed here.

\footnotetext{
${ }^{14}$ Specifically, Bhattacharjee and Holly (2008) assumed that: (a) sum of squares for each row was unity (row standardisation), (b) idiosyncratic error variances for the equations corresponding to the 3 internal members were equal (partial homoscedasticity), and (c) interactions between the internal members were symmetric (partial symmetry).
} 


\section{Connections Weights}

Ellipses proportional to influence

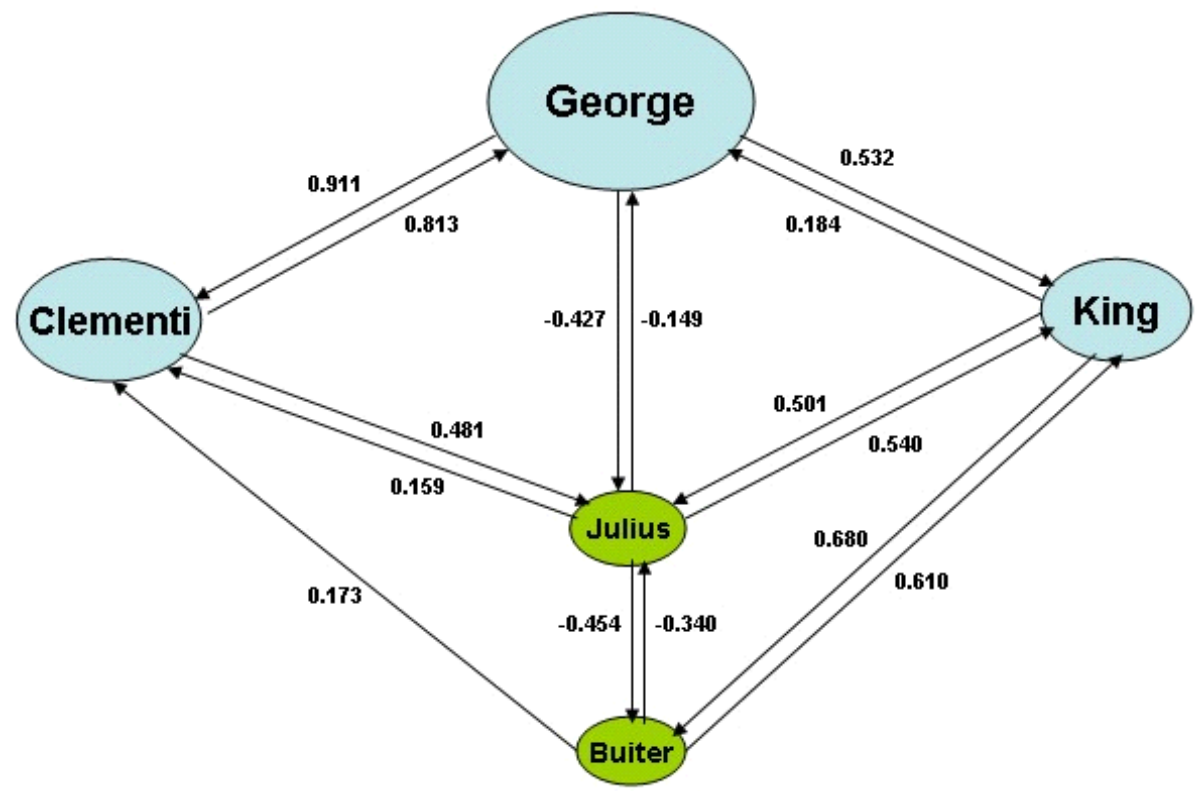

Figure 2: 


\section{Conclusions}

In this paper we proposed estimation and inference on interaction weights in social networks and committees. Our method is based on GMM, and based on moment conditions motivated by the literature on dynamic panel data models. We place special emphasis on interval censored regression. Both aspects of the addressed problem are hard. First, estimation in censored regression models is difficult except under very strong assumptions. While assumptions may be strong in some applications, we also point out alternative sets of assumptions and alternative ways to proceed in such cases. Second, estimation of interaction weights is also difficult and, as shown in Bhattacharjee and Jensen-Butler (2005), a partially identified problem. Existing estimation methods in Bhattacharjee and Jensen-Butler (2005) and Pesaran and Tosetti (2007) placed strong restrictions on the structure of the weights matrix, which we do not. At the same time, we make assumptions on moment conditions, and largely for simplicity, also on the nature of endogeneity and on the distribution of the error terms. Which of these approaches contributes to more credible inferences is a question which is partly application specific, and partly to be addressed through simulations.

An important advantage of the proposed methods is that they are simple to implement, and as our application to interactions within a monetary policy committee shows, they also contribute to very useful inferences. Specifically, our empirical study of voting behaviour within the Bank of England's MPC provides good support for the above method as well as our theoretical model, and uncovers new evidence on the process of monetary policy decision making. In particular, we provide more extensive evidence on the strength and nature of cross-member interactions and provide valuable insights on the process of decision making within the MPC. The evidence of strong interactions found here requires further examination within the context of appropriate theory on incentives and strategic behaviour within a monetary policy committee. The emerging theoretical literature in this area may provide interesting new insights on this aspect.

Our empirical application also contributes towards understanding the process of network formation in a committee setting. The emerging and very active theoretical literature provides additional insights into the stability of different network architectures under assumptions on information sharing and bargaining. Empirical insights using our proposed methods can help in understanding these issues more fully. 


\section{References}

[1] Ahn, S. and P. Schmidt (1995). Efficient estimation of models for dynamic panel data, Journal of Econometrics 68 (1995), pp. 5-28.

[2] Amemiya, T. (1973). Regression analysis when the dependent variable is truncated normal. Econometrica 41, 997-1016.

[3] Anselin, L. (1988). Spatial Econometrics: Methods and Models. Kluwer Academic Publishers: Dordrecht, The Netherlands.

[4] Anselin, L. (2002), Under the hood. Issues in the specification and interpretation of spatial regression models, Agricultural Economics, 27, 247-267.

[5] Anselin, L., R. Florax and S. Rey (2003). Econometrics for spatial models: recent advances. In L. Anselin, R. Florax and S. Rey (Eds.) Advances in Spatial Econometrics. Berlin: Springer-Verlag.

[6] Aoki, K. (2003). On the optimal monetary policy response to noisy indicators. Journal of Monetary Economics 50(3), 501-523.

[7] Arellano, M. and Bond, S. (1991). 'Some tests of specification for panel data: Monte Carlo evidence and an application to employment equations', Review of Economic Studies, Vol. 58, pp. 277-297.

[8] Austen-Smith, D. and Banks, J.S. (1996). Information aggregation, rationality, and the Condorcet jury theorem. American Political Science Review 90, 34-45.

[9] Bala, Venkatesh and Sanjeev Goyal (2003). "A Noncooperative Model of Network Formation." Econometrica, 68, 1181-1229.

[10] Bates, J.M. and Granger, C.W.J. (1969). The combination of forecasts. Operations Research Quarterly 20, 451-468.

[11] Bhattacharjee, A., Higson, C., Holly, S. and Kattuman, P. (2008). Macroeconomic instability and business exit: determinants of failures and acquisitions of UK firms. Forthcoming in Economica. 
[12] Bhattacharjee, A. and Holly, S. (2005). Inflation targeting, committee decision making and uncertainty: the case of the Bank of England's MPC. Cambridge Working Papers in Economics 0530, Faculty of Economics, University of Cambridge, UK.

[13] Bhattacharjee, A. and Holly, S. (2008). Inflation targeting, committee decision making and uncertainty: the case of the Bank of England's MPC. Cambridge Working Papers in Economics 0530, Faculty of Economics, University of Cambridge, UK.

[14] Bhattacharjee, A. and Jensen-Butler, C. (2005). Estimation of spatial weights matrix in a spatial error model, with an application to diffusion in housing demand. CRIEFF Discussion Paper No. 0519, University of St. Andrews, UK.

[15] Blundell, R. and Bond, S. (1998). 'Initial conditions and moment restrictions in dynamic panel data models', Journal of Econometrics, Vol. 87, pp. $115-143$.

[16] Blundell, R.W. and Powell, J.L. (2003). Endogeneity in nonparametric and semiparametric regression models. In M. Dewatripont, L.P. Hansen and S.J. Turnsovsky (eds.) Advances in Economics and Econometrics, Chapter 8.

[17] Blundell, R.W. and Powell, J.L. (2004). Endogeneity in Semiparametric Binary Response Models. Review of Economic Studies 71, 655-679.

[18] Blundell, R.W. and Smith, R. (1986) An exogeneity test for the simultaneous equation tobit model with an application to labor supply. Econometrica 54, 679-685.

[19] Bond, S., Bowsher, C. and Windmeijer, F. (2001). Criterion-based inference for GMM in autoregressive panel data models. Economics Letters 73, 379-388.

[20] Bonhomme, S. and Robin, J.M. (2006). Using High-Order Moments to Estimate Linear Independent Factor Models. IFS Discussion Paper, Institute for Fiscal Studies. 
[21] Britton, E., Fisher, P.G., Whitley, J.D. (1998). The inflation report projections: understanding the fan chart. Bank of England Quarterly Bulletin 38, 30-37.

[22] Case, A.C. (1991), Spatial Pattern in Household Demand, Econometrica, 59, 953-965.

[23] Chevapatrakul, T., Mizen, P., Kim, T.-H. (2001). Using rules to make monetary policy: the predictive performance of Taylor rules versus alternatives for the United Kingdom 1992 - 2001. Mimeo.

[24] Coakley, J., Fuertes, A.M., and Smith, R. (2002), A Principal Components Approach to Cross-Section Dependence in Panels, Birkbeck College Discussion Paper 01/2002.

[25] Conley, T.G. (1999), GMM Estimation with Cross Sectional Dependence, Journal of Econometrics, 92, 1-45.

[26] Conley, T.G., and Molinari, F. (2007). Spatial correlation robust inference with errors in location or distance. Journal of Econometrics 140(1), 76-96.

[27] Conley, T.G., and Topa, G. (2002), Socio-economic Distance and Spatial Patterns in Unemployment, Journal of Applied Econometrics, 17, 303327.

[28] Conley, T.G., and Topa, G. (2003). Identification of local interaction models with imperfect location data. Journal of Applied Econometrics, $18,605-618$.

[29] Dempster, A., Laird, N. and Rubin, D. (1977). Maximum likelihood for incomplete data via the EM algorithm. Journal of the Royal Statistical Society Series B 39 (1), 1-38.

[30] Doran, H. and P. Schmidt (2006). GMM estimators with improved finite sample properties using principal components of the weighting matrix with application to the dynamic panel data model, Journal of Econometrics 133 (2006), pp. 387-409.

[31] Dutta, Bhaskar and Matthew O. Jackson (2003). Networks and Groups: Models of Strategic Formation. Springer Verlag, Berlin. 
[32] Felgenhauer, M. and Grüner, H.P. (2008). Committees and special interests. Journal of Public Economic Theory 10, 219-243.

[33] Fingleton, B. (2003). Externalities, economic geography, and spatial econometrics: conceptual and modeling developments. International Regional Science Review 26(2), 197-207.

[34] Gascoigne, J., Turner, P. (2003). Asymmetries in Bank of England monetary policy. Sheffield Economic Research Paper Series No. 2003007.

[35] Gerlach-Kristen, P. (2004). Is the MPC's voting record informative about future UK monetary policy?. Scandinavian Journal of Economics 106 (2), 299-314.

[36] Gerling, K., Grüner, H.P., Kiel, A. and Schulte, E. (2005). Information acquisition and decision making in committees: a survey. European Journal of Political Economy, 21(3), 563-597.

[37] Giacomini, R. and Granger, C.W.J. (2004). Aggregation of space-time processes. Journal of Econometrics 118, 7 - 26.

[38] Gibbons, S and Machin, S. (2005). Valuing rail access using transport innovations. Journal of Urban Economics 57, 148-169.

[39] Goyal S. (2005). Strong and weak links. Journal of the European Economic Association April-May 2005 3(2-3):608-616.

[40] Goyal S. (2007) Connections: an Introduction to the Economics of Networks. Princeton University Press.

[41] Goyal S. and Vega-Redondo, F. (2007). Structural holes in social networks. Journal of Economic Theory 137, 460-492.

[42] Granovetter, Mark S. (1973). "The Strength of Weak Ties." American Journal of Sociology, 78, 1360-1380.

[43] Greene, W. (1993). Econometric Analysis. Prentice-Hall, Inc.

[44] Grüner, H.P. and Kiel, A. (2004). Collective decisions with interdependent valuations. European Economic Review 48, 1147-1168. 
[45] Hall, A.R. (2004). Generalized Method of Moments. Oxford University Press: Oxford.

[46] Hansen, L. (1982). Large sample properties of generalized method of moments estimators. Econometrica 50, 1029-1054.

[47] Hausman, J.A. and Taylor, W.E. (1983). Identification in linear simultaneous equations models with covariance restrictions: an instrumental variables interpretation. Econometrica 51, 1527-1550.

[48] Hausman, J.A., Newey, W.K. and Taylor, W.E. (1987). Efficient estimation and identification of simultaneous equation models with covariance restrictions. Econometrica 55, 849-874.

[49] Holly, S., Pesaran, M.H. and Yamagata, T. (2008), A Spatio-Temporal Model of House Prices in the US, by forthcoming in the Journal of Econometrics

[50] Hong, H. and Tamer, E. (2003). Inference in censored models with endogenous regressors. Econometrica 71, 905-932.

[51] Ichimura, H. (1993). Semiparametric least squares (SLS) and weighted SLS estimation of single-index models. Journal of Econometrics 58, 71120 .

[52] Issing, O. (2002). Monetary policy in a world of uncertainty. Presented at the Economic Policy Forum, Banque de France, Paris, 9 Dec. 2002.

[53] Jackson, Matthew O. and Asher Wolinsky (1996). "A Strategic Model of Economic and Social Networks." Journal of Economic Theory, 71, $44-74$.

[54] Jovanovic, B. and Rousseau, P.L. (2002). The Q-theory of mergers. American Economic Review, Papers and Proceedings, 92, 198-204.

[55] Kapoor, M., Kelejian, H.H., and Prucha, I.R. (2007). Panel data models with spatially correlated error components. Journal of Econometrics 140(1), 97-130.

[56] Kelejian, H.H., and Prucha, I.R. (1999), A Generalized Moments Estimator for the Autoregressive Parameter in a Spatial Models, International Economic Review, 40, 509-533. 
[57] Kelejian, H.H., and Prucha, I.R. (2004). Estimation of simultaneous systems of spatially interrelated cross sectional equations. Journal of Econometrics 118, 27-50.

[58] Kelejian, H.H., and Prucha, I.R. (2007). HAC estimation in a spatial framework. Journal of Econometrics 140(1), 131-154.

[59] King, M. (2002). The Monetary Policy Committee five years on. Address to the Society of Business Economists, London, 22 May 2002 (available from http://www.bankofengland.co.uk/speeches/speaker.htm).

[60] Kleibergen, F. (2007). Generalizing weak instrument robust IV statistics towards multiple parameters, unrestricted covariance matrices and identification statistics. Journal of Econometrics 139, 181-216.

[61] Lewbel, A. (2000). Semiparametric qualitative response model estimation with unknown heteroscedasticity and instrumental variables. Journal of Econometrics 97, 145-177.

[62] Lewbel, A. (2004). Simple estimators for hard problems: endogeneity in discrete choice related models. Mimeo.

[63] Li, H., Rosen, S. and Suen, W. (2001). Conflicts and common interests in committees. American Economic Review 91, 1478-1497.

[64] Magnac, T. and Maurin, E. (2008). Partial identification in monotone binary models: discrete regressors and interval data. Review of Economic Studies 75, 835-864.

[65] Matsen, E. and Røisland, Ø. (2005). Interest rate decisions in an asymmetric monetary union. European Journal of Political Economy 21, 365384 .

[66] McLachlan, G. and Krishnan, T. (1997). The EM Algorithm and Extensions. John Wiley.

[67] Newey, W.K. (1984). A method of moments interpretation of sequential estimators. Economics Letters 14, 201-206.

[68] Newey, W. and West, K.D. (1987). Hypothesis Testing with Effcient Method of Moments Estimation. International Economic Review 28, 777-787. 
[69] Orphanides, A. (2003). Monetary policy evaluation with noisy information. Journal of Monetary Economics 50 (3), 605-631.

[70] Pesaran, M.H. (2006), Estimation and Inference in Large Heterogenous Panels with Multifactor Error Structure, Econometrica, 74, 967-1012.

[71] Pesaran, M.H., Schuermann, T. and Weiner, S. (2004), Modelling Regional Interdependencies using a Global Error-Correcting Macroeconometric Model, Journal of Business and Economics Statistics, 22, 129-162.

[72] Pesaran, M.H. and Tosetti, E. (2007). Large Panels with Common Factors and Spatial Correlations.Working Paper CWPE 0743, Faculty of Economics, University of Cambridge.

[73] Pinkse, J. and Slade, M.E. (2007). Semi-structural models of advertising competition. Journal of Applied Econometrics 22, 1227-1246.

[74] Pinkse, J., Slade, M.E. and Brett, C. (2002). Spatial price competition: a semiparametric approach. Econometrica 70, 1111-1155.

[75] Robertson, D., and Symons, J. (2000). Factor residuals in SUR regressions: estimating panels allowing for cross sectional correlation. Unpublished Manuscript, Faculty of Economics, University of Cambridge.

[76] Sibert, A. (2002). Monetary policy with uncertain central bank preferences. European Economic Review 46, 1093-1109.

[77] Sibert, A. (2003). Monetary policy committees: individual and collective reputations. Review of Economic Studies 70 (3), 649-665.

[78] Svensson, L. (1997). Inflation forecast targeting: implementing and monitoring inflation targets. European Economic Review 41 (6), 1111-1146.

[79] Townsend, R.M. (1983). Forecasting the forecasts of others. Journal of Political Economy 91, 546-588.

[80] Wansbeek, T. and Meijer, E. (2001). Measurement error and latent variables. In Baltagi, B.H. (Ed.), A Companion to Theoretical Econometrics. Oxford: Basil Blackwell, Chapter 8, 162-179. 